\title{
RIESGOS LABORALES PSICOSOCIALES. PERSPECTIVA ORGANIZACIONAL, JURÍDICA Y SOCIAL*
}

\section{Adriana Camacho Ramírez** Daniela Rocío Mayorga **}

Fecha de recepción: 28 de noviembre de 2016

Fecha de evaluación: 29 de mayo de 2017

Fecha de aprobación: 27 de junio de 2017

Artículo de reflexión

DOI: http://dx.doi.org/10.18359/prole.3047

Forma de citación: Camacho, A. \& Mayorga, D. R. (2017). Riesgos laborales psicosociales. Perspectiva organizacional, jurídica y social. Revista Prolegómenos Derechos y Valores, 20, 40, 159-172. DOI: http://dx.doi. org/10.18359/prole.3047

\section{Resumen}

Dadas las consecuencias negativas en la productividad, clima organizacional, salud y relaciones interpersonales entre los trabajadores, las empresas están cada vez más interesadas en identificar las causas, prevenirlas y controlarlas. Se pretende establecer las consecuencias de los conflictos laborales, como riesgos psicosociales, en los trabajadores, así como en las empresas y terceros, para lo cual se realiza una aproximación a las definiciones y clasificaciones básicas, mayormente influenciadas desde la psicología; para después analizar el impacto en grupos que históricamente se encuentran discriminados laboralmente, finalizando con algunas recomendaciones.

\section{Palabras clave:}

Conflictos laborales, riesgos psicosociales, impacto de los riesgos laborales, grupos discriminados laboralmente.

\footnotetext{
El presente artículo se elaboró en el marco de la línea de investigación "Mobbing, conflictos laborales y mal clima organizacional", del Grupo de Investigación Derecho Privado de la Facultad de Jurisprudencia del Colegio Mayor de Nuestra Señora del Rosario (Universidad del Rosario) (Bogotá, Colombia).

* Abogada de la Universidad del Rosario (Bogotá, Colombia). Abogada de la Universitá degli Studi di Milano (Milán, Italia). Magíster en Derecho Laboral y Administración del Personal en la Universitá Cattolica del Sacro Cuore di Milano (Milán, Italia). Profesora de carrera de la Universidad del Rosario y miembro del Grupo de Investigación Derecho Privado de la misma universidad. Correo electrónico: adriana.camacho@urosario.edu.co

*** Administradora de Negocios Internacionales de la Universidad del Rosario (Bogotá, Colombia), integrante de la línea de investigación "Mobbing, conflictos laborales y mal clima organizacional" del Grupo de Investigación Derecho Privado de la Universidad del Rosario. Correo electrónico: daniela.mayorga@urosario.edu.co
} 


\title{
PSYCHOSOCIAL LABOR RISKS. AN ORGANIZATIONAL, LEGAL AND SOCIAL PERSPECTIVE
}

\begin{abstract}
Summary
Given the negative consequences over the productivity, organization climate, health, and interpersonal relations between co-workers, companies are more willing to identify the causes in order to prevent and control them. The consequences of labor dispute are intended to be established as psychosocial risks over the employees, as well as over the companies and third parties. For this reason, an approach upon the definition and basic classification has been done, mostly influenced by Psychology; therefore, allowing us to analyze the impact over groups that historically have been found to be discriminated in the workplace. Some recommendations will be given at the end.
\end{abstract}

\section{Keywords:}

Labor conflicts, psychosocial risks, labor risks' impact, labor discriminated groups.

\section{RISCOS LABORAIS PSICOSSOCIAIS. PERSPECTIVA ORGANIZACIONAL, JURÍDICA E SOCIAL}

\begin{abstract}
Resumo
Dadas às consequências negativas na produtividade, clima organizacional, saúde e relações interpessoais entre os trabalhadores, às empresas estão cada vez mais interessadas em identificar as causas, para preveni-las e controla-las. Pretende-se estabelecer as consequências dos conflitos laborais, como riscos psicossociais, nos trabalhadores, bem como nas empresas e terceiros, para o qual se faz uma aproximação para as definições e classificações básicas, principalmente influenciadas a partir da psicologia, para depois analisar o impacto sobre os grupos que são historicamente discriminados no trabalho, terminando com algumas recomendações.
\end{abstract}

\section{Palavras-chave:}

Conflitos laborais, riscos psicossociais, impacto dos riscos laborais, grupos discriminados no trabalho

\section{Introducción}

Durante las últimas décadas el mundo se ha visto enfrentado a grandes cambios en las dinámicas y prácticas que rigen la vida en sociedad. Nos encontramos en un contexto de globalización y competitividad caracterizado por la presencia de avanzada tecnología y la necesidad de obtener resultados de calidad lo más pronto posible. Los vertiginosos cambios en el mercado del trabajo, en las condiciones laborales y en las dinámicas empresariales, han provocado "nuevos riesgos" que atentan contra la salud de los trabajadores física, mental y emocionalmente.

Entre los "nuevos factores" tenemos los contratos precarios (alejados de los estables de la época fordista), las nuevas formas de empleo, la inseguridad laboral (o su sentimiento), la intensificación del trabajo, el trabajo emocional y el 
conflicto trabajo-familia, como los más importantes según la Agencia Europea de Seguridad y Salud en el Trabajo (2012). En medio de este ambiente se desarrollan las relaciones laborales de hoy en día, y siendo el recurso humano el componente más significativo de las organizaciones, parecería que el estudio de estos riesgos es, infortunadamente, secundario.

El análisis de los conflictos laborales y de los riesgos psicosociales es el interés de esta investigación, así como su impacto en los trabajadores de la empresa, en la organización misma y en los terceros, poniendo especial atención en aquellos grupos que históricamente son discriminados laboralmente: mujeres, migrantes, comunidad LGBT, personas con discapacidad, jóvenes y mayores de cincuenta años. Nuestra intención es abordar el tema desde una perspectiva teórica, organizarlo y presentar no solo algunos focos problemáticos sino un inocente primer inicio al estudio de la superación de los mismos desde el punto de vista práctico-organizacional.

Para su desarrollo se utilizó el método cualitativo que permitió examinar los conceptos manejados transversalmente en varias disciplinas (en especial la psicología y la sociología) y el método deductivo para poder exponer nuestras recomendaciones sobre todo desde el enfoque empresarial.

\section{A. Riesgos laborales psicosociales. Definición, factores y clases}

Hasta hace algunos años, la preocupación de las empresas por los trabajadores se reducía a cumplir con unos mínimos normativos en materia laboral, tales como el pago oportuno de salarios o cierto número de horas a trabajar por semana y poco a poco esta preocupación fue direccionándose hacia los riesgos físicos y ambientales en el trabajo en general (Moreno, 2011). Este pensamiento viene evolucionando trayendo cambios significativos como

[...] la consideración de una concepción biopsicosocial de la salud y la necesidad de que esta sea promovida en los lugares de trabajo. Ello ha supuesto una concepción de la prevención de los riesgos y accidentes laborales que incluye los llamados riesgos ergonómicos y psicosociales. Ha llevado también a la consideración de los daños psicosociales como una de las consecuencias de una inadecuada prevención de riesgos (Peiró, 2004, p. 180).

En este entendido, los Estados y las organizaciones orientan sus esfuerzos hacia una comprensión integral de la dimensión humana, con el supuesto que, si el trabajador se encuentra en buenas condiciones de salud física y psicológica, habrá un impacto positivo en la productividad y disminución de costos en materia de atención médica y acompañamiento.

\section{Definición}

Los riesgos psicosociales laborales "son situaciones laborales que tienen una alta probabilidad de dañar gravemente la salud de los trabajadores, física, social o mentalmente" (Moreno, 2011, p. 7). Estos son riesgos reales, bien sea que se evidencien inmediatamente o a mediano $y$ largo plazo, y son tan determinantes como los riesgos físicos, los accidentes y las enfermedades derivadas del trabajo (Moreno y Garrosa, 2013), que son los riesgos históricamente considerados en el trabajo.

El riesgo psicosocial, que no es un simple conflicto de los que se suelen presentar en cualquier relación, surge en el momento que ciertos factores pueden desencadenar hechos o situaciones con grandes probabilidades de causar efectos negativos en la salud del trabajador, lo cual finalmente tendrá repercusiones también en la organización (Gómez, Hernández y Méndez, 2014).

\section{Factores}

La Organización Internacional del Trabajo (OIT) nos acerca a una definición precisa de los factores psicosociales, no sin antes indicar el nivel de dificultad del tema, "los factores psicosociales 
en el trabajo son complejos y difíciles de entender, dado que representan el conjunto de las percepciones y experiencias del trabajador y abarcan muchos aspectos" (OIT, 1986, p. 3). También señala:

[...] los factores psicosociales en el trabajo consisten en interacciones entre el trabajo, su medio ambiente, la satisfacción en el trabajo y las condiciones de organización, por una parte, y por la otra, las capacidades del trabajador, sus necesidades, su cultura y su situación personal fuera del trabajo, todo lo cual, a través de percepciones y experiencias, puede influir en la salud, en el rendimiento yen la satisfacción en el trabajo (OIT, 1986, p. 3).

Teniendo en cuenta lo anterior, es posible identificar dos componentes determinantes en el desarrollo de los riesgos psicosociales y son: los factores organizacionales y los factores laborales.

\section{Factores organizacionales}

Comprenden:

- Política y filosofía de la organización: relación trabajo-familia, gestión de los recursos humanos, política de seguridad y salud, responsabilidad social corporativa y estrategia empresarial.

- Cultura de la organización: política de relaciones laborales, información organizacional, comunicación organizacional, justicia organizacional y supervisión/liderazgo.

- Relaciones industriales: clima laboral, representación sindical y convenios colectivos.

\section{Factores laborales}

Comprenden:

- Condiciones de empleo: tipo de contrato, salario y proyección laboral.

- Diseño del puesto: rotación de puestos y trabajo grupal.

- Calidad en el trabajo: uso de habilidades laborales, demandas laborales, autonomía y capacidad de control, seguridad física en el trabajo, apoyo social y horas de trabajo (España, 2010).

Dichos factores ejercen influencia en los trabajadores, pues impactan su vida laboral, social y familiar.

\section{Clases}

La Agencia Europea de Seguridad y Salud en el Trabajo (2012) detectó los riesgos psicosociales más relevantes, ya que son los que mayores efectos negativos crean en la salud del trabajador. Son: el estrés laboral, la violencia en el trabajo, el mobbing y el acoso sexual.

Como se considera que los riesgos psicosociales afectan los derechos humanos y fundamentales del trabajador de tal manera que resulta necesario legislar su prevención y sanción, "han sido recogidos en la mayoría de constituciones nacionales actuales, y [...] por lo mismo tienen formas de protección legal, tanto a nivel nacional como internacional" (Moreno, 2011, p. 8). Grosso modo, nos permitimos analizar las cuatro clases de riesgos psicosociales laborales:

\section{El estrés}

Es una respuesta adaptativa del organismo ante una situación de presión o amenaza externa (Peiró y Lira, 2013). Los factores de estrés psicosocial más comunes son los que se registran en la tabla 1.

\section{La violencia en el trabajo}

Son "aquellos incidentes en donde las personas son abusadas, amenazadas o asaltadas en circunstancias relacionadas con su trabajo, suponiendo un reto, explícito o implícito, para su seguridad, bienestar y salud" (Wynne, Clarkin, Cox y Griffiths, 1997, p. 1, citados en Díaz y Báez, 2013). Son de índole psicológica y también física. Dentro de las conductas identificadas como violentas están: el abuso emocional (comporta- 
Tabla 1. Factores de estrés psicosocial

\begin{tabular}{|c|c|}
\hline Contenido del trabajo & $\begin{array}{l}\text { Falta de variedad en el trabajo, ciclos cortos de trabajo, trabajo fragmentado y sin sentido, bajo } \\
\text { uso de habilidades, alta incertidumbre, relación intensa }\end{array}$ \\
\hline Sobrecarga y ritmo & Exceso de trabajo, ritmo del trabajo, alta presión temporal, plazos urgentes de finalización \\
\hline Horarios & $\begin{array}{l}\text { ambio de turnos, cambio nocturno, horarios inflexibles, horario de trabajo imprevisible, jor- } \\
\text { adas largas o sin tiempo para la interacción }\end{array}$ \\
\hline Control & $\begin{array}{l}\text { Baja participación en la toma de decisiones, baja capacidad de control sobre la carga de } \\
\text { trabajo }\end{array}$ \\
\hline Ambiente y equipos & $\begin{array}{l}\text { Malas condiciones de trabajo, equipos d } \\
\text { los equipos, falta de espacio personal, e }\end{array}$ \\
\hline $\begin{array}{l}\text { Cultura o } \\
\text { y funcion }\end{array}$ & $\begin{array}{l}\text { Mala comunicación interna, bajos niveles de apoyo, falta de definición de las propias tareas o } \\
\text { de acuerdo con los objetivos organizacionales }\end{array}$ \\
\hline $\begin{array}{l}\text { Relaciones } \\
\text { interpersonales }\end{array}$ & $\begin{array}{l}\text { Aislamiento físico o social, escasas relaciones con los jefes, conflictos laborales, falta de apoyo } \\
\text { social }\end{array}$ \\
\hline Rol en la organización & Ambigüedad de rol, conflicto de rol y responsabilidad sobre personas \\
\hline Desarrollo de carreras & $\begin{array}{l}\text { Incertidumbre o paralización de la carrera profesional, baja o excesiva promoción, pobre } \\
\text { remuneración, inseguridad contractual }\end{array}$ \\
\hline $\begin{array}{l}\text { Relación } \\
\text { trabajo-familia }\end{array}$ & $\begin{array}{l}\text { Demandas conflictivas entre el trabajo y la familia, bajo apoyo familiar, problemas duales de } \\
\text { carrera }\end{array}$ \\
\hline Seguridad contractual & Trabajo precario, trabajo temporal, incertidumbre de futuro laboral, insuficiente remuneración \\
\hline
\end{tabular}

Fuente: elaboración propia.

mientos hostiles), la incivilidad (conductas rudas e irrespetuosas), el acoso psicológico o mobbing y el acoso sexual. Por la contundencia de estos dos últimos tipos de violencia en el trabajo, se estudian de manera paralela en esta sección.

\section{El mobbing}

El acoso psicológico en el trabajo o acoso laboral lo entiende Caamaño Rojas como

[...] un comportamiento antijurídico, pluriofensivo de derechos fundamentales y está conformado por hostigamientos sistemáticos y reiterados de palabra, obra u omisión del empleador o de uno o más trabajadores, o de estos de consuno, contra uno o más trabajadores que atentan contra su dignidad o salud y afectan sus condiciones $\mathrm{u}$ oportunidades de empleo u ocupación (2011, p. 218).
La finalidad de este fenómeno puede ser de distinta naturaleza, como obtener la renuncia forzada del acosado, buscar una situación propicia para lograr su posterior despido o conseguir la abstención de la defensa jurídica de sus derechos (Gamonal y Prado, 2006), o simplemente como diría Iñaki Piñuel y Zabala "eliminarl[o] de la organización” (2001, p. 188).

\section{El acoso sexual}

Puede entenderse como "la conducta indeseada de carácter sexual presentada en el trabajo que es evaluada por el receptor como ofensiva, que excede sus recursos o que amenaza su bienestar" (Fitzgerald, Swan y Magley, 1997, p. 15). Igualmente, la directiva $2002 / 73$ de la Comunidad Europea sobre la igualdad de trato entre hombres y mujeres lo define como 
[...] toda situación en que se produce cualquier comportamiento verbal, no verbal o físico no deseado de índole sexual con el propósito o el efecto de atentar contra la dignidad de una persona, en particular cuando se crea un entorno intimidatorio, hostil, degradante, humillante u ofensivo (Parlamento Europeo y Consejo de la Unión Europea, 2002).

El acoso sexual es, como veremos, un problema que afecta principalmente a las mujeres.

\section{B. Los conflictos laborales como riesgos psicosociales}

Consideramos que los conflictos laborales son la base de los riesgos psicosociales, toda vez que

[...] son una tensión o choque generado en el marco del ambiente de trabajo, y que nos atrevemos a indicar que siempre se suscitará porque como en cualquier campo interpersonal se estará expuesto a tensiones, luchas, ideas e intereses distintos. Mal manejados desencadenarán una serie de estrés laboral, $\mathrm{u}$ otros problemas, con la potencialidad de causar un daño psicológico, físico o social en los trabajadores (Gil-Monte, 2009).

En efecto, cada individuo está formado por unos valores, intereses, metas, pensamientos y vivencias diferentes, $y$ al momento de interactuar con otras personas se ve enfrentado a lidiar con posturas contrarias a la suya, es aquí cuando surgen las confrontaciones, haciendo del conflicto un fenómeno inherente al ser humano. Lo anterior se aplica en los distintos ámbitos de la vida en sociedad, especialmente en el ambiente laboral, pues los trabajadores deben convivir día a día en situaciones de estrés cumpliendo las funciones encomendadas por los empleadores.

El conflicto laboral no es malo per se, pues puede conducir a la construcción de un grupo de trabajo más unido, incluyente y respetuoso; el problema surge cuando los conflictos no se abordan de forma adecuada y se tornan tóxicos, llevando incluso a la violencia laboral. Es decir, que un conflicto laboral mal manejado aumenta el riesgo para los trabajadores de sufrir algún perjuicio en su salud, y por ello la labor de prevención se vuelve indispensable para evitar situaciones indeseadas.

El conflicto puede presentarse de dos formas (Ortiz, 2009). Una, conflicto laboral horizontal, entendido como la tensión entre trabajadores con un mismo cargo; sectores o grupos de trabajo al interior de la organización; nacionalidades o etnias; trabajadores nacionales e inmigrantes; trabajadores calificados y rasos; trabajadores sindicalizados y no sindicalizados; trabajadores fijos y temporales, entre otros. En concreto, conflictos generados dentro de las relaciones de trabajo sin que se halle presente el elemento de la subordinación, con causas atribuibles a factores como las condiciones de trabajo, cultura y clima organizacional. Dos, conflicto vertical, el cual se presenta entre empleador y trabajador o entre gerencia y trabajadores.

Una vez presentado el conflicto o tensión, su positiva resolución tiene distintos impactos dependiendo de si estamos ante un conflicto vertical u horizontal. Así, creemos que cuando se resuelve el conflicto horizontal, hay construcción de mejores condiciones en el espacio laboral compartido; mientras que, al resolver el conflicto vertical, se logra una apreciación y valoración del otro como alguien con diferente rol, pero en iguales condiciones de derechos, dignidad y oportunidades.

\section{Impacto de los riesgos laborales psicosociales en trabajadores, empresas y terceros}

Los riesgos psicosociales son uno de los riesgos laborales más grandes a los que se enfrentar un trabajador, pues pueden involucrar a otros individuos, y sus causas y efectos pueden ser múltiples. Dentro de las consecuencias más importantes de los riesgos laborales de tipo psicosocial se tienen (España, 2010): 


\section{Para el trabajador}

- Físicas (European Agency for Safety and Health at Work, 2000): estrés, hipertensión arterial, alteraciones metabólicas, consumo de sustancias psicoactivas como el alcohol, desórdenes músculo-esqueléticos, trastornos cardiovasculares, ansiedad e irritabilidad.

- Psicológicas: enfermedades mentales, desórdenes afectivos, depresión, baja autoestima y desmotivación.

- Conflicto trabajo-familia: grandes cargas laborales que no facilitan cumplir con las responsabilidades familiares, bajos niveles de compromiso con la organización, ansiedad, consecuencias psicológicas y hostilidades en casa.

- Violencia laboral y/o acoso laboral: un conflicto laboral mal llevado puede derivar en violencia laboral o incluso en prácticas de acoso laboral.

\section{Para la empresa/empleador}

Los riesgos psicosociales son riesgos para las empresas y organizaciones, pues repercuten sobre sus niveles de funcionalidad, productividad, eficacia y eficiencia. Los riesgos psicosociales, como el conjunto de riesgos para la salud en el trabajo, no son ajenos a la línea de negocio de la organización (España, 2010, p. 76).

Sino que la afectan internamente, disminuyendo sus posibilidades de ganancias. Lo anterior comporta que haya organizaciones disfuncionales impidiendo tener la productividad deseada.

Los principales riesgos que corren las empresas se manifiestan en aspectos tangibles como ausencia de compromiso laboral, insatisfacción, baja productividad, mal clima organizacional, mayor rotación de trabajadores y aumento de costos. Son los siguientes:

- Absentismo: el trabajador no se presenta a trabajar (Flores-Sandí, 2006). Las bajas laborales por enfermedad representan grandes costos que deben asumir las empresas. Licencias remuneradas, remplazos temporales o desaceleración de la producción son muestras de que no se puede hablar de salud como un problema exclusivo de los empleados, pues tienen repercusiones directas en la organización.

- Presentismo: a diferencia del ausentismo, el trabajador se presenta a trabajar, pero en razón de su condición médica, no es productivo. El costo del presentismo es oculto, porque el trabajador está en el trabajo aunque no está cumpliendo eficazmente. Dicha falta de productividad, con todos sus inconvenientes y conflictos, la asume la organización y el propio afectado (Flores-Sandí, 2006).

- Intenciones de abandono: la falta de motivación unida a la insatisfacción en el puesto de trabajo lleva a que los trabajadores busquen nuevas oportunidades de empleo en otras organizaciones. La empresa termina afecta$\mathrm{da}$, pues pierde la posibilidad de contar con grandes talentos a consecuencia de un mal manejo de los conflictos, lo cual incrementa la rotación del personal, aumentando costos al tener que estar realizando continuamente búsquedas de talentos, inducciones, capacitaciones y tiempos de adaptación a la empresa.

\section{Para terceros}

Los accidentes y daños son el mayor impacto observado. Sobre todo, se reconoce en las empresas que ofrecen servicios, puesto que en sectores como el de la salud, por ejemplo, se puede afectar la calidad en el cuidado de los pacientes (España, 2010). Los riesgos psicosociales y en especial los conflictos laborales trascienden la empresa y pueden repercutir en el interés más grande que tiene esta: sus clientes.

Tal como se pudo apreciar, los conflictos y los factores de riesgo psicosocial "perjudican las relaciones que mantiene el trabajador en una organización, incurriendo sobre las características 
del clima organizacional" (Abello y Lozano, 2013). Veamos brevemente esas relaciones.

\section{Clima organizacional y riesgos psicosociales}

¿Por qué hablar de clima organizacional? Es una pregunta de gran relevancia que permite analizar y estudiar el impacto de los riesgos psicosociales. El clima organizacional o clima laboral "hace referencia al conjunto de condiciones existentes en la organización que tienen impacto sobre el comportamiento individual" (Paris-Marcano, 2014, p. 41). Como se puede deducir, es una expresión que abarca numerosos factores que pueden ser internos y/o externos; involucra a la organización y sus esfuerzos por brindar un ambiente óptimo de trabajo, pero también las interacciones entre los trabajadores, sus percepciones y su bienestar.

Por esto, autores como Neuman y Barón (1998) indican que el clima organizacional es una variable trascendental a la hora de analizar los efectos de la estructura organizacional en los comportamientos de los individuos de la empresa, ya que finalmente sí hay una influencia entre el ambiente en el que se trabaja y las conductas de las personas.

Es responsabilidad de la empresa brindar todas las herramientas, infraestructura, directrices y políticas que permitan desarrollar a cabalidad las funciones encomendadas; en otras palabras, la organización debe generar un ambiente de trabajo propicio para su personal. A su vez, los trabajadores, como seres humanos que se relacionan e interactúan en dichos espacios $y$ en condiciones de subordinación, tienen el compromiso de dar lo mejor de sí para cumplir con las funciones encargadas y de armonizar y adaptarse a la empresa relacionándose con sus compañeros de trabajo de tal forma que se genere un ambiente de tolerancia y respeto mutuo a pesar de las diferencias. Cuando ambos componentes van de la mano, se aumenta la satisfacción laboral, incrementando la motivación de los trabajadores (por consiguiente, su rendimiento y productividad) y se controlan los riesgos psicosociales.

\section{E. Riesgos psicosociales y grupos laboralmente discriminados}

Desde 1944 con la Declaración de Filadelfia (OIT, 2015), pasando por tratados internacionales, recomendaciones e informes, se busca alcanzar la igualdad en materia laboral, pero no es una labor fácil, especialmente para aquellos grupos que, debido a prejuicios en la sociedad o por diferencias culturales, físicas e ideológicas, son discriminados. Analizaremos el impacto de los riesgos psicosociales en estos grupos y daremos algunas ideas, sobre todo para los empresarios con respecto a su inclusión y al trato igualitario.

\section{Por motivos de género: las mujeres}

La OIT nos informa que en una cultura predominantemente masculina,

[...] las mujeres que sobresalen, sufren estigma y discriminación, esto no tiene que ver con su capacidad de liderazgo o competencia sino con la cultura sexista y machista a la que son sometidas en los procesos educativos, ya sea en la escuela, en la familia, en la iglesia o en el trabajo (OIT, 2015).

Las mujeres siguen considerándose el sexo débil a pesar de que actualmente cuentan con igual o mejor formación profesional que los hombres, pero un ambiente machista hace que sean vulnerables y discriminadas en el desempeño de sus funciones, lo que se evidencia en aspectos como menor remuneración, menores beneficios o peores condiciones laborales. Lo anterior, genera frustraciones y situaciones de conflicto en las mujeres al percibir que pese a que cuentan con los mismos méritos, se les da un trato desigual.

Uno de los riesgos psicosociales más evidentes en este grupo de trabajadores es el acoso sexual, sobre todo cuando se trabaja con un número elevado de varones o en contextos masculinizados (McDonald, 2012). En estos ambientes 
es usual también que se presente el "sexismo" que son aquellas conductas que desvalorizan a las mujeres como chistes sexuales, exhibición de imágenes pornográficas, etc. (Pernas, Olza, Roman y Ligero, 2000), lo cual además crea un ambiente hostil que puede degenerar aún más en conflictos laborales, estrés y violencia. Las estadísticas informan que el acoso sexual es en extremo mayor en las mujeres que en los hombres (Rubio de Medina, 2011), siendo especialmente vulnerables a este flagelo las más jóvenes, las económicamente dependientes, las solteras o divorciadas y las migrantes (OIT, 2011).

Por otra parte, uno de los mayores problemas actuales de este grupo, derivado de los factores de tipo psicosocial es el estrés.

Son diversas las investigaciones que han definido, que mientras mayor sea la cantidad de roles que la persona debe desempeñar, mayor será la probabilidad de que sufra estrés, por lo cual afectaría en mayor número a las mujeres, debido a la sobrecarga de roles (Gómez et al., 2014, p.10).

Ellas con frecuencia se encuentran mayormente afectadas por diversos conflictos laborales, derivados de la difícil situación de no poder conciliar su vida laboral y familiar. Precisamente, la sociedad machista que aún hoy en día considera a la mujer pilar de la casa y de la crianza (pero que no cuenta con políticas sociales y laborales que permitan esa interacción), traerá consecuencias negativas para la salud física y psicológica de las trabajadoras como conflictos y estrés en el trabajo.

\section{Por motivos raciales}

Este grupo discriminado comprende (OIT, 2007): los trabajadores de un color de piel diferente a la blanca (principalmente personas de raza negra), las minorías étnicas, los pueblos indígenas y los trabajadores migrantes.

Dichos grupos se ven perjudicados por "siglos de tratamiento desigual en todas las esferas de la vida, sumados a persistentes y profundas desigualdades por motivos étnicos y socioeconómicos" (OIT, 2007). La OIT nos indica que "en general, hay una imagen de inferioridad o percepción de desagrado hacia estos grupos" (2007). Los migrantes, especialmente, se perciben como una amenaza a la estabilidad laboral de sus compañeros. En efecto, una de las acusaciones más frecuentes y generalizadas es que los trabajadores migrantes desequilibran la estabilidad laboral de los nacionales, "ya que aceptan empleos a cambio de salarios inferiores, y dan lugar a la desintegración de las prestaciones y de las condiciones laborales en el país de acogida" (OIT, 2011).

Muchas veces los migrantes no son vinculados laboralmente como lo serían los nacionales. La inmigración suele aceptar menores condiciones laborales "considerándola un valor primario, fuente necesaria de ingresos para la subsistencia personal y para la remesa de apoyo económico familiar. Este contexto favorece las prácticas abusivas" (Moreno y Rodríguez, 2013, p. 61).

\section{Por pertenecer a grupos LGBT}

Las personas que conforman estos grupos se enfrentan a discriminaciones directas e indirectas por su condición. La OIT al respecto manifiesta que su realidad es muy problemática y que muchas veces

[...] esa opresión es introyectada y la propia persona pasa a tener dificultades para aceptarse y respetarse a sí misma. Esta expresión de la diversidad humana cercenada hace la vida más difícil y el ambiente organizacional más pobre, menos productivo y con una homogeneidad artificial apoyada en una represión que termina por perjudicar a todos (OIT, 2015).

A parte de la discriminación laboral, consideramos que este grupo podría sufrir de estrés y mobbing. Aquí es muy importante tener en cuenta los conflictos laborales que los tienen como protagonistas y solucionarlos a tiempo, so pena de que se conviertan vertiginosamente 
en cualesquiera de los riesgos psicosociales mencionados.

\section{Por discapacidad}

Las tasas habituales de desempleo en este grupo de personas suelen ser más altas que las de la población en general "al margen de las posibles tareas y del nivel de discapacidad, sin duda alguna por el estigma social asociado a sus limitaciones" (Moreno y Rodríguez, 2013, p. 60).

En efecto, hay prejuicios que generan graves estigmas al momento de tratar laboralmente a las personas con discapacidad, pues "existe el mito de presentarlos como dependientes o en estado de lástima" (Castro, 2001, p.16), sin embargo, como nos lo indican las investigaciones "lo correcto es visualizarlos sin exagerar sus incapacidades, con el objeto de que gocen de un sistema real de oportunidades y de trato" (Castro, 2001, p.16).

La discriminación laboral es un riesgo latente en este grupo de personas. En particular porque generalmente la organización debe adaptarse a sus capacidades y necesidades, en vez del normal comportamiento derivado de la adaptación del trabajador a la empresa.

"Dada su heterogeneidad, las discapacidades afectan de distinta forma la capacidad de sus víctimas para trabajar, y estas necesitan diversos tipos de medidas de adaptación, lo cual origina, a su vez, otras clases de discriminación" (OIT, 2015). Es responsabilidad de los empleadores dar las herramientas necesarias para que el proceso de adaptación sea lo menos engorroso posible. La discriminación en el ambiente laboral para estos trabajadores implica que

[...] se les suelen asignar las tareas que son mal remuneradas, que no requieren cualificaciones y son de baja categoría. Estas personas pertenecen al grupo de trabajadores caracterizados como "los últimos en ser contratados, pero los primeros en ser despedidos", que son más vulnerables a los efectos de la recesión (OIT, 2015).
La contratación es precaria ya que, a manera de ejemplo, según informes europeos del 2010, el $25,95 \%$ de las personas discapacitadas contaba con un contrato a término indefinido, mientras que el 74,05 \% con contratos temporales (Moreno y Rodríguez, 2013).

Por las características de los puestos que ocupan y las concepciones de que no son tan productivos, es que en tiempos de recesión las empresas no los toman como indispensables para el desarrollo organizacional. Ello perjudica la imagen organizacional externa, pues estas no son vistas como organizaciones incluyentes $y$ socialmente responsables.

Desde otro enfoque, en cambio, este grupo de trabajadores presenta otro problema para ellos y para su vinculación laboral por la situación de vulnerabilidad que se identifica y que quiere superarse. Es el caso de las políticas estatales que se acogen buscando la inclusión y el trabajo decente para ellos, pero que a la larga producen el efecto contrario. Como ejemplo podemos citar el denominado "fuero de discapacidad" por el cual tal trabajador no podrá ser despedido sin justa causa y en todo caso con autorización del órgano laboral competente. Estos límites empresariales, aunque con base en una política de inclusión, han aumentado hoy en día, a nuestro juicio, la discriminación de las personas en condición de discapacidad.

\section{Por motivos de edad}

Los mayores de cincuenta años, a pesar de ser la generación con mayor experiencia, son considerados lentos o casi inservibles. La modernización empresarial (OIT, 2015) necesita constantemente y de una manera inmediata una flexibilidad laboral en cargos, sedes y horarios que no son usuales en la generación de hace algunos años, acostumbrada a tener claramente identificado sus labores, sus jefes, su puesto de trabajo, etc., y a la cual los cambios le producen miedo, estrés y muchas veces simplemente estas personas son incapaces física, mental y aptitudinalmente de seguir. Por ello 
[...] es necesario reconocer que los propios trabajadores de edad avanzada tienen necesidades diferentes. Al ofrecerles diversas opciones respecto al modo de ordenar su tiempo de trabajo, los empleadores se benefician tanto de mantener la experiencia y las cualificaciones de estos empleados, como de la transmisión de su conocimiento de la organización a los trabajadores más jóvenes (OIT, 2015).

Este grupo de trabajadores está expuesto, en nuestro concepto, a todos los riesgos psicosociales. En el otro extremo se encuentran los muy jóvenes, quienes también por razones de su edad sufren estos riesgos, ya que con la crisis económica y en el empleo, la menor seguridad contractual y la poca autonomía laboral, "son especialmente vulnerables a incidentes relacionados con el acoso laboral y sexual [...] y a la violencia en sus diferentes formas" (Moreno y Rodríguez, 2013, p. 60).

\section{Discriminación múltiple: acumulación de factores}

Hace referencia a aquellos casos en los que se juntan distintos factores en una sola persona, lo cual potencia la posibilidad de ser discriminada en su ambiente laboral o de ser acosada moralmente (Hirigoyen, 1999). Y este tipo de ataques múltiples se reconoce por ejemplo en "las mujeres con discapacidades que sufren mayor tasa de violencia y abusos sexuales" (OIT, 2003). Recientemente, la misma OIT afirmó:

La intensidad o la gravedad de las desventajas que afrontan dependen del número de características personales que suscitan discriminación y de la manera en que estas actúan entre sí. Por ejemplo: ser mujer, anciana, discapacitada y negra, en cuyo caso puede ser objeto de formas de discriminación sumamente complejas (2015).

$\mathrm{Al}$ ser sujetos doble o triplemente vulnerables, se convierten en individuos de especial cuidado por parte de las empresas, o al menos, ese debería ser el objetivo.

\section{F. Recomendaciones a los empresarios}

Es importante tener en cuenta que el derecho al trabajo no alude solo al acceso al empleo y a su estabilidad,

[...] se trata también del derecho a un ambiente inclusivo donde todos, sin encontrar barreras o impedimentos a su carrera, puedan desarrollar plenamente su potencial, recibir un trato respetuoso y equitativo $y$ disfrutar de libertad para poder expresarse sin para ello tener que sufrir opresión o violencia (OIT, 2015).

Sin duda alguna, los empleadores pueden incidir positivamente en la disminución de los riesgos psicosociales a los que se ven enfrentados los grupos laboralmente discriminados. Promover un ambiente laboral sin discriminación, inclusivo y respetuoso "genera mayor productividad, disminuye el absentismo y la exposición a riesgos, mejora la calidad de los servicios y las relaciones con los diferentes públicos" (OIT, 2015). El ambiente laboral debe incentivar las oportunidades de desarrollo individual y profesional de los trabajadores, de todos sin excepción, y de hacerlos sentir parte de la empresa.

Queremos aclarar que nuestra visión no es la de fomentar una discriminación invertida, en donde todo se les deba a aquellos grupos discriminados con base en la creencia de que por su vulnerabilidad per se, deban tener un trato preferencial. Lo que recomendamos es que se dé igual oportunidad e igual trato a todos, con políticas dirigidas dentro de la colectividad.

Al promover un clima organizacional adecuado, se genera un doble beneficio, pues se construye una sociedad más tolerante y respetuosa donde se garantiza la salud de los trabajadores, pero también las empresas obtienen beneficios propios. Las organizaciones respetuosas e inclusivas, que valoran la diversidad, "son potencialmente más creativas, calificadas, innovadoras y capacitadas para tratar con un mundo también diverso, en rápido y profundo proceso de cambio" (OIT, 2003). 
Hacemos un llamado frente a la necesidad de identificar valores clave en la cultura organizacional para promoverlos de manera transversal en todas las actividades y grupos de influencia que tenga la organización, tales como relación con los proveedores, buenas prácticas, atención al cliente e interacción entre los trabajadores.

Los riesgos psicosociales deben evaluarse, cuantificarse y una vez identificados, crear unas oportunas acciones de mejora, un establecimiento de protocolo antirriesgos y una adecuada prevención. Lo primero que debe existir es una seria voluntad organizacional de activarse frente a estos trastornos por el bien propio y el de sus trabajadores. Detectar el patrón negativo de la empresa es el primer paso para realizar un procedimiento idóneo, por ello es importante estar atento a las quejas, al abstencionismo, al turn over, a la baja en la productividad, a las denuncias por acoso laboral, a otros hostigamientos, entre otros.

Consideramos primordial que tales identificaciones se clasifiquen también desde el punto de vista subjetivo, valorando individualmente la percepción del talento humano. De este modo los grupos históricamente discriminados laboralmente podrían tener un enfoque propio, que haga más inclusivo los protocolos antirriesgos, que los tenga más en cuenta y que facilite escuchar las opiniones de ellos y de todos los grupos socialmente implicados. Así, la estrategia de prevención y de intervención podría ser más efectiva, pues está influenciada por la realidad de la empresa que no es igual a las otras empresas, y que necesita soluciones a su medida.

Repetimos que no se trata de tener un trato preferencial y diferencial con estos grupos, sino de crear unas estrategias ad hoc para ellos, pues como indicamos aquí, estas personas no solo pueden ser víctimas de los riesgos psicosociales y de los conflictos laborales que cualquier trabajador puede sufrir en una empresa, sino de otros adicionales y propios, pues el impacto en ellos es mayor.

Como instrumento adicional consideramos trascendental la inspección y el acompañamiento tanto del Estado como de las administradoras de riesgos laborales, con campañas de información y de prevención.

\section{Conclusiones}

Inconscientemente las empresas pueden propiciar o influir en la generación de un mal clima organizacional. Aspectos como la precarización laboral, infraestructura inadecuada, líderes autoritarios o políticas internas, pueden desencadenar conflictos entre los mismos trabajadores o la afectación en su salud. Paradójicamente son las organizaciones las que resultan perjudicadas si no se toman el trabajo de invertir los recursos necesarios en su protección, de tal forma que después no se lamenten por los altos costos a los que se exponen.

Las empresas deben activar protocolos y realizar procedimientos para identificar sus conflictos, sus riesgos propios y aprender a tratarlos. Invitamos a las organizaciones a que dentro de sus estrategias antirriesgos dediquen un capítulo especial a la prevención y sanción de aquellas conductas discriminatorias, de acoso laboral y de conflictos en general frente a su nómina, pero también frente a aquellos grupos que se encuentran precisamente en un mayor riesgo como las mujeres, los migrantes, las personas con discapacidad, los pertenecientes a la comunidad LGBT y los mayores de cincuenta años, pues las empresas deben comprometerse en la promoción del respeto y la igualdad entre sus trabajadores. Para ello, es recomendable que, desde sus cimientos, se incluyan valores en pro de la inclusión, por ejemplo, ampliando la perspectiva en su misión, visión, reglamento interno y valores institucionales.

Creemos que con motivar a los trabajadores para que haya un adecuado clima organizacional, se puede lograr que cada uno se desenvuelva de acuerdo con sus características, pensamientos y cultura personal. De igual manera es importante promover valores, igualdad y respeto hacia las diferencias. No consideramos que sea una tarea fácil, pero sí creemos que debe existir un inicio 
serio desde cada empresa, posiblemente de la mano de las administradoras de riesgos en el trabajo y del Estado. Esperamos que futuras investigaciones centren su interés en lo práctico de los procedimientos de protocolos antirriesgos o en hipótesis de prevención real de los mismos.

\section{Referencias}

Abello, Á. J. \& Lozano, D. M. (2013). Importancia de los factores de riesgo psicosocial y clima organizacional en el ámbito laboral. Disponible en: http:// repository.urosario.edu.co/bitstream/ handle/10336/4693/20888400-2013. pdf?sequence $=1$

Agencia Europea para la Seguridad y Salud en el Trabajo. (2014). Riesgos psicosociales en Europa: prevalencia y estrategias de prevención. Disponible en: doi: $10.2802 / 29383$

Caamaño, E. A. (2005). El derecho a la no discriminación en el empleo. Santiago de Chile: LexisNexis.

Castro, J. (2001). Discriminación en las relaciones laborales. Disponible en: http:// www.inspecciondeltrabajo.cl/1601/articles-65173_recurso_1.pdf

Díaz, L. \& Báez, C. (2013). Salud laboral. Madrid: Ediciones Pirámide.

España. (2010). Factores y riesgos psicosociales, formas, consecuencias, medidas y buenas prácticas. Madrid: Ministerio de Trabajo e Inmigración de España, Universidad Autónoma de Madrid. Disponible en: http://www. insht.es/InshtWeb/Contenidos/Documentacion/PUBLICACIONES\%20PROFESIONALES/factores\%20riesgos\%20psico.pdf

European Agency for Safety \& Health at Work. (2000). Research on work-related stress. Luxemburgo: Office for Official Publications of the European Communities.

Fitzgerald, L., Swan, S. \& Magley, V. (1997). But was it really sexual harassment? Legal, behavioral and psychological de- finitions of the workplace victimization of women. Needham: Heights.

Flores-Sandí, G. (2006). "Presentismo": potencialidad en accidentes de salud. Acta Médica Costarricense, 48(1).

Gamonal, S. \& Prado, P. (2006). El mobbing o acoso moral laboral. Santiago de Chile: LexisNexis.

Gil-Monte, P. (2009). Algunas razones para considerar los riesgos psicosociales en el trabajo y sus consecuencias en la salud pública. Revista Española de Salud Pública, pp. 169-173.

Gómez, P., Hernández, J. \& Méndez, M. D. (2014). Factores de riesgo psicosocial y satisfacción laboral en una empresa chilena del área de la minería. Ciencia \& Trabajo, 16(49), pp. 9-16. Disponible en: https://dx.doi.org/10.4067/S071824492014000100003

Hirigoyen, M. F. (1999). El acoso moral, el maltrato psicológico en la vida cotidiana. Barcelona: Paidós.

McDonald, P. (2012). Workplace sexual harassment 30 years on: a review of the literature. International Journal of Management Reviews, 14, pp. 1-17. Disponible en: doi:10.1111/j.1468-2370.2011.00300.x

Moreno, B. (2011). Factores y riesgos laborales psicosociales: conceptualización, historia y cambios actuales. Revista Med Segur Trab, 57, suplemento 1 , pp. 1-262.

Moreno, B. \& Garrosa, E. (2013). Salud laboral. En: Salud laboral, riesgos laborales, psicosociales y bienestar laboral. Madrid: Ediciones Pirámide.

Moreno, B. \& Rodríguez, R. (2013). Sociología de la salud laboral. En: Salud laboral, riesgos laborales, psicosociales y bienestar laboral. Madrid: Ediciones Pirámide.

Neuman, J. \& Barón, R. (1998). Workplace violence and workplace aggression: evidence concerning specific forms, potential causes, 
and preferred targets. Journal of Management, 24(3), pp. 391-419. Disponible en: doi:10.1177/014920639802400305

Organización Internacional del Trabajo. (1986). Factores psicosociales en el trabajo: reconocimiento y control. Ginebra: OIT.

Organización Internacional del Trabajo. (2003). El derecho al trabajo decente en las personas con discapacidades. Ginebra: OIT.

Organización Internacional del Trabajo. (2003). La hora de la igualdad en el trabajo. Informe global con arrego al seguimiento de la Declaración de la OIT relativa a los principios y derechos fundamentales en el trabajo. Disponible en: http://www.ilo.org/ wcmsp5/groups/public/—dgreports/dcomm/—publ/documents/publication/ wcms_publ_9223128714_sp.pdf

Organización Internacional del Trabajo. (2007). La igualdad en el trabajo: afrontar los retos que se plantean. Disponible en: http:// www.ilo.org/wcmsp5/groups/public/-dgreports/—dcomm/—-webdev/documents/publication/wcms_082609.pdf

Organización Internacional del Trabajo. (2011). Revista Trabajo, 72. Disponible en: http://www.ilo.org/wcmsp5/groups/ public/-dgreports/—-dcomm/documents/publication/wcms_165642.pdf

Organización Internacional del Trabajo. (2015). OIT. Disponible en: http://civilisac.org/civilisweb/ wp-content/uploads/Declaraci\%C3\%B3nde-Filadelfia-1944-OIT-1.pdf

Organización Internacional del Trabajo. (2015). Promoción de los derechos humanos de personas LGBT en el mundo del trabajo. Disponible en: http://www.ilo.org/ wcmsp5/groups/public/—americas/— ro-lima/—-ilo-brasilia/documents/publication/wcms_425065.pdf

Ortiz, I. D. (2009). Conflicto y resolución en el mundo laboral. Bogotá: Universidad Nacional de Colombia.
Paris-Marcano, M. (2014). Factores antecedentes no individuales que inciden en el acoso psicológico en el trabajo: el caso del acoso laboral institucionalizado. Juncos, Puerto Rico: Tesis doctoral Universidad del Turabo. Disponible en: http://ut.suagm.edu/sites/default/files/ uploads/Centro-Estudios-Doctorales/Tesis_Doctorales/2014/MParis.pdf

Parlamento Europeo y Consejo de la Unión Europea. (2002). Directiva 2002/73 relativa a la aplicación del principio de igualdad de trato entre hombres $y$ mujeres en lo que se refiere al acceso al empleo, a la formación y a la promoción profesionales, y a las condiciones de trabajo. Bruselas: Diario Oficial de las Comunidades Europeas.

Peiró, J. M. (2004). El sistema de trabajo y sus implicaciones para la prevención de los riesgos psicosociales en el trabajo. Actualiza Revista, 3(2), pp. 179-186.

Peiró, J. M. \& Lira, E. (2013). Estrés laboral: nuevas y viejas fórmulas en salud laboral. Madrid: Ediciones Pirámide.

Pernas, B., Olza, J., Roman, M. \& Ligero, J. (2000). El alcance del acoso sexual en el trabajo en España. Madrid: Secretaría Confederal de la Mujer.

Piñuel y Zabala, I. (2001). Mobbing. Cómo sobrevivir al acoso psicológico en el trabajo. Santander: Sal Terrae.

Rubio de Medina, M. (2011). Los conceptos de acoso laboral (mobbing), acoso sexual y acoso por razón de sexo y su relación con la igualdad de oportunidades. Madrid: Tecnos.

Wynne, R., Clarkin, N., Cox, T. \& Griffiths, A. (1997). Guidance on the prevention of violence at work. Luxemburgo: Europpean Comission. 